\title{
Excitotoxic Septal Lesions Result in Spatial Memory Deficits and Altered Flexibility of Hippocampal Single-Unit Representations
}

\author{
Stefan Leutgeb and Sheri J. Y. Mizumori \\ Program in Neuroscience and Department of Psychology, University of Utah, Salt Lake City, Utah 84112
}

The septal nuclei are reciprocally connected with the hippocampal formation and contribute importantly to spatial and memory processing. Using excitotoxic lesions of the septal area, we investigated whether neurodegeneration in subcortical projections to hippocampus can compromise flexible information processing by hippocampal single units. In agreement with the mild effects of excitotoxic septal lesions on hippocampal physiology compared with fimbria-fornix lesions and septal inactivation, we observed limited lesion effects on single-unit activity. The location specificity of hippocampal complex spike cells remained unchanged, but a less reliable locationdependent discharge was observed in experimental animals with a pronounced postoperative working memory deficit. Testing in the absence of ambient illumination and in a new environment revealed that the spatial correlates of complex spike cells in lesioned animals may rely on a more limited set of sensory cues. Altered sensory cues resulted in a significantly

The septal nuclei are part of a larger brain system that supports navigational and memory functions. Disconnecting subcortical areas, including the septum, from hippocampus by fimbria-fornix lesions or temporarily inactivating the medial septal area results in an impairment of spatial memory tasks (Sutherland and Rodriguez, 1989; Mizumori et al., 1990; Whishaw and Jarrard, 1995). These manipulations also effectively reduce hippocampal slow wave activity in the $8-12 \mathrm{~Hz}$ band (theta activity) and alter the spatial correlates of hippocampal cells. Control hippocampal complex spike cells of rodents selectively discharge at restricted locations in the environment (O'Keefe and Dostrovsky, 1971; O'Keefe, 1976) and continue to identify the same locations when tested repeatedly (Muller et al., 1987; Thompson and Best, 1990). Fimbria-fornix lesions reduce the percentage of hippocampal units with location-dependent discharge, decrease hippocampal single-unit activity in consistent locations, and decrease the control of distal landmarks over the location of complex spike cell activity (Miller and Best, 1980; Shapiro et al., 1989). Although permanent fornix lesions affect place fields of all hippocampal subareas to a similar extent, temporary inactivation of the medial septum and its fibers of passage results in disintegrated fields in

\footnotetext{
Received Dec. 2, 1998; revised May 14, 1999; accepted May 14, 1999.

This work was supported by the National Science Foundation (IBN 9514880), the Human Frontiers Science Program (HFSP RG0110), National Institutes of Health (MH 58755), and a University of Utah research fellowship. We thank Dr. Kristen Keefe for assisting with the histological analysis and Jill Howard, Dr. Robert Marc, and Dr. Scott Rogers for their support with image processing.

Correspondence should be addressed to Dr. Sheri J. Y. Mizumori, Department of Psychology, University of Utah, 390 S. 1530 E. Room 502, Salt Lake City, UT 84112. Copyright (C) 1999 Society for Neuroscience $0270-6474 / 99 / 196661-12 \$ 05.00 / 0$
}

different response pattern between the control and lesion group in the new environment, a situation that normally results in place field reorganization. Such a group difference was not observed during dark testing, a condition in which place field reorganization is less prominent. A contribution of hippocampal interneurons to the observed alterations in the spatial properties of the principal cells was suggested by decreased theta modulation in the lesioned group. Because excitotoxic lesions result in memory deficits that resemble age-related memory problems in the absence of age-related degenerative processes, we suggest that septal neurodegeneration could directly contribute to those behavioral changes with advanced age that correlate with functional alterations in the hippocampal formation.

Key words: medial and lateral septum; hippocampus; place cells; spatial working memory; aging; acetylcholine; GABA projection neurons

only the hilar/CA3 and not the CA1 subarea of hippocampus (Mizumori et al., 1989).

Septal projections to hippocampus have been implicated in contributing to memory problems of aged individuals (Markowska et al., 1995). Excitotoxic lesions of the septum produce behavioral consequences that resemble age-related learning problems but do not alter hippocampal function as profoundly as fimbria-fornix lesions or septal inactivation (Green and Arduini, 1954; Stewart and Vanderwolf, 1987; Hagan et al., 1988; Mizumori et al., 1989, 1990; Gallagher et al., 1993; Leung et al., 1994). Theta activity and acetylcholine neurotransmission are partially preserved after excitotoxic lesions, and the same pattern is seen with advanced age (Stewart and Vanderwolf, 1987; Leung et al., 1994; Markowska et al., 1995). Excitotoxic lesions of the septal area may therefore be more directly relevant than fimbria-fornix lesions or medial septal inactivation for understanding the relative contribution of the septal area and hippocampus to agerelated memory impairments. Use of the lesion technique in young animals can reveal whether neurodegeneration in subcortical structures alters hippocampal single-unit activity in the absence of additional age-related changes in the hippocampal formation.

We explored the hypothesis that the septal nuclei importantly regulate plasticity of hippocampal place representations, a phenomenon known to change with old age (Barnes et al., 1997; Tanila et al., 1997a,b), by recording the spatial correlates of hippocampal complex spike cells and interneurons in freely moving animals after septal lesions by quinolinic acid. Because earlier studies have shown that fornix lesions decrease the dependence of hippocampal fields on distal cues (Miller and Best, 1980; Shapiro 
et al., 1989), we recorded hippocampal units in the absence of ambient illumination to identify whether place fields of animals with excitotoxic septal lesions are less dependent on well learned visual landmarks or whether they fail to integrate multiple sensory modalities. A subset of the units was also recorded in a second room to explore whether relying on limited sensory information could result in a decreased likelihood of developing a distinct representation for an environment that shares geometric features with the familiar environment.

\section{MATERIALS AND METHODS}

Subjects. Thirteen male Long-Evans rats were obtained from a commercial source (Simonsen Laboratories, Gilroy, CA). The animals were 7-12 months old at the start of the experimental procedures. They were housed individually with free access to water. Food was restricted to maintain the animals at a minimum of $80 \%$ of their ad libitum body weight. Training and recording sessions were performed only during the light phase of a $12 \mathrm{hr}$ light/dark cycle.

Apparatus. An elevated eight-arm radial maze with a $19.5 \mathrm{~cm}$ center platform and $58 \mathrm{~cm} \times 5.5 \mathrm{~cm}$ arms was used for training and recording. The proximal half of each arm was hinged and could be lowered by remotely controlled motors to hinder access to the distal part of the arm, or it could be raised to the level of the center platform to provide access. The maze was placed in a quadratic enclosure surrounded by black curtains with a set of four visual cues, each $50 \mathrm{~cm}$ high and $80 \mathrm{~cm}$ wide, posted inside the curtains. A second room, which resembled the familiar room, was used to test the animals in a novel environment. The maze in the second room had the same specifications as the one in the familiar room and was also placed in a quadratic enclosure. Five visual cues that were entirely different from those in the familiar room were placed inside the curtains; two were positioned in the corners and three were hung on the walls.

Behavioral procedures. The animals were pretrained to retrieve chocolate milk from the end of the maze arms. During pretraining the animals were allowed to freely explore all eight maze arms, and the arms were rebaited when the animal had consumed the food rewards. Training began on the day after an animal had entered each arm of the maze at least once. During all subsequent training sessions, the animals were first placed on the center platform, and a pseudorandom sequence of four arms was then presented. One arm was initially raised and access to the next arm in the sequence was provided when the animal had entered the previous arm. Access to all arms was given after the fourth arm in the sequence, and the trial was continued until the remaining food rewards had been retrieved. Re-entries into previously visited arms were counted as working memory errors. The next trial started after the animal was confined to the center platform for $2 \mathrm{~min}$, and the session was continued for a maximum of $1 \mathrm{hr}$ or eight trials. Preoperative training continued until the animals had completed eight trials within $1 \mathrm{hr}$ for 7 consecutive days. The animals were retrained to the same criterion after surgery.

Surgery. The animals were deprived of food and water before surgery and deeply anesthetized with pentobarbital $(50 \mathrm{mg} / \mathrm{kg}$, i.p.; Nembutal, Abbott Laboratories, Chicago, IL). The level of anesthesia was monitored continuously and additional doses $(10 \mathrm{mg} / \mathrm{kg}$, i.p.) were given as needed. The skull was exposed by a skin incision, and small drill holes were placed dorsal to the medial septal area and, bilaterally, dorsal to hippocampus. The glutamate agonist quinolinate (Sigma, St. Louis, MO) was dissolved in PBS $(21 \mathrm{mg} / \mathrm{ml})$ and injected into the medial septum [anteroposterior (AP) +0.7 , lateral (L) \pm 0.0 , dorsoventral (DV) 4.5 below dura] with a 33 gauge cannula connected to a Hamilton syringe. A volume of $0.5 \mu \mathrm{l}$ of either the drug or vehicle solution was infused, and the needle was left in place for an additional 5 min to limit diff usion along the needle tract. Recording electrodes were manufactured as stereotrodes by twisting two $20 \mu \mathrm{m}$ lacquer-coated tungsten wires (California Fine Wire, Grover City, CA). The stereotrodes were then coated with epoxylite, inserted into a 30 gauge stainless steel cannula, and cut with a pair of sharp scissors protruding $\sim 1.5 \mathrm{~mm}$ from the distal end of the cannula. Two or three stereotrodes were mounted on a microdrive and placed stereotaxically at AP -3.0 to $-5.0, \mathrm{~L} \pm 2.0-2.5$, and an initial depth of $1.5 \mathrm{~mm}$ below the dural surface. A $114 \mu \mathrm{m}$ stainless steel reference electrode was lowered into the corpus callosum and secured to the skull along with the microdrives by using dental cement and stainless steel screws. One of the skull screws served as an electrical ground. Bicillin (300,000 U, i.m.) was given as an antibacterial prophylactic at the end of surgery, and the animals were allowed free access to food and water for 1 week before again being placed on a food-restricted schedule.

Recording procedures. The signal from each electrode was preamplified by a headstage holding an array of unity gain FET amplifiers. Incoming signals were then amplified 2,000-10,000 times by a differential amplifier (Neurolynx, Tucson, AZ), band-pass-filtered between 600 and $6000 \mathrm{~Hz}$, and transmitted to an analog-to-digital (A/D) board in a pentium-based computer system. The data acquisition program (Datawave Technologies, Longmont, $\mathrm{CO}$ ) recorded a $1 \mathrm{msec}$ sequence of each signal that exceeded a preset threshold (sampling frequency: $26-32 \mathrm{kHz}$ per channel). The headstage also held an infrared light-emitting diode that was centered on the animal's head. The infrared signal was recorded by a video camera mounted in the ceiling of the recording room. A tracking system (Dragon Tracker) identified the position of the animal with a spatial resolution of $256 \times 256$ (sampling frequency, $20 \mathrm{~Hz}$ ). The $x-y$ coordinates of the animal's position on the maze were time-stamped and stored along with the single-unit data.

After postsurgical retraining, the animals were screened daily for single units while they were confined to the center platform of the eight-arm radial maze. All recording channels were checked for single units by using an audio monitor and an oscilloscope. The microdrives were advanced gradually until single units were identified or for a maximum of $90 \mu \mathrm{m} / \mathrm{d}$. Spike discharges of individual units were separated by using an on-line spike separation software (Datawave Technologies) that generates scatterplots of spike waveform parameters (e.g., amplitude, width) recorded on each of the two stereotrode wires. Discharges of single units were identified with a window discriminator by first outlining the cluster of spike discharges on the scatterplot showing the relative peak amplitudes and then refining the boundaries in additional projections. The data were replayed off-line, and clusters were reexamined by using amplitude, spike width, phase angle, and waveform templates as parameters to separate single units.

Behavioral testing. Daily recording sessions for each set of single units continued until visual inspection revealed that the cluster boundaries were different from the previous day or for a maximum of three phases of behavioral testing. (1) Each unit was initially recorded for eight baseline trials or, alternatively, in a sequence of 15 trials that included five trials in the standard baseline condition (light), five trials without ambient illumination (dark), and an additional five trials with the maze lights on (lights restored). (2) Testing on subsequent days included a session that began in darkness for five trials and continued in light for five trials. (3) After testing the units in the familiar recording room, a sequence of six daily recording sessions commenced that included testing in a novel environment. Testing in the second recording room started with two baseline sessions of eight trials, each of which lasted at least 30 min, and continued with recording sessions in the familiar and novel testing environment on alternate days to compare complex spike cell activity in each of the testing environments. Single-unit activity in the novel environment was tested only once for each animal. Data are reported only for animals with a complete sequence of recordings. The electrodes were advanced on the day when the spike amplitudes had become unstable or after the recording sequence was completed. A new sequence of behavioral testing commenced when a different set of single units was encountered. When units could not be identified on any of the recording electrodes, the animals were given eight baseline sessions of spatial memory training at least every second day. Behavioral testing without recording single units assured that asymptote performance was maintained in control and lesioned animals.

Data analysis. Hippocampal complex spike cells and interneurons were identified on the basis of discharge rates and waveform characteristics (Ranck, 1973; Shen et al., 1997). Examination of the peak-to-valley (negative to positive) duration of the waveforms revealed a bimodal frequency distribution with a minimum at $250 \mu \mathrm{sec}$. Spikes with a duration of $>250 \mu \mathrm{sec}$ and average rates of $<5 \mathrm{~Hz}$ were classified as complex spike cells, and the validity of the criteria was confirmed by inspecting the autocorrelation histograms. Conversely, cells with a duration of $<250 \mu \mathrm{sec}$ and mean rates of $>5 \mathrm{~Hz}$ were identified as interneurons, and interneurons were further subdivided into rhythmic and nonrhythmic units based on visual inspection of the autocorrelation histograms. A small fraction of the total number of hippocampal units did not fit either criteria and was not further analyzed.

Recording sessions were analyzed by dividing the session into trials and by eliminating data that were recorded during intertrial intervals. Place fields of hippocampal complex spike cells and location-dependent discharges of hippocampal interneurons were quantified by dividing the 
maze into 16 segments based on location (one of eight maze arms) and direction of movement (outbound or inbound). The rate was calculated by counting the number of spike discharges for each bin, then dividing the count by occupancy time. A specificity score was calculated by dividing the highest rate by the average rate of the 15 remaining bins, and a reliability score was calculated as the proportion of trials (in percent) when the maximum trial rate occurred in the same bin as the overall maximum rate. Place fields were also quantified by binning the data into a 64 by 64 grid with each pixel corresponding to a quadratic $2.4 \times 2.4 \mathrm{~cm}$ field on the maze. Rate maps were calculated by counting the number of spikes at each location and dividing the spike count by occupancy time. The rate maps were used to calculate the information content and covariance indices, which are designed to convey a similar meaning as specificity and reliability, respectively, but without assuming that the fields best correspond to 16 predefined bins. The spatial information content score was calculated as described previously (Skaggs et al., 1993, Jung et al., 1994; Markus et al., 1995). The scores of the present study (see below) were consistently higher than reported previously (Markus et al., 1994, 1995). The difference may result from methodological rather than actual discrepancies. Preprocessing of the rate maps (Markus et al., 1995) or differences in the total number of bins (Markus et al., 1994) are likely sources for the differing numerical values. The information content score should be interpreted as indicating field size in $\log _{2}$ units rather than reflecting information theoretical measurements. Theoretical accounts of hippocampal functions have suggested that larger field sizes may be computationally more efficient (Samsonovich and McNaughton, 1997). The maze area in the current recording setup corresponded to approximately 1000 (or $2^{10}$ ) pixels, and the theoretical upper limit for the information content score is 10 for a unit that is only active in exactly one bin of the maze.

The covariance index was calculated by generating rate maps for each trial independently and then entering the rate in identical locations as repeated observations into the statistical calculation of the covariance (Hays, 1994). If the elements of the vector $\mathbf{X}_{\mathrm{i}}$ correspond to the mean rate in each location and $\mathrm{E}\left(\mathbf{X}_{\mathrm{i}}\right)$ to the arithmetic mean of trial $i$, the covariance for $n$ trials is defined as $\operatorname{cov}\left(\mathbf{X}_{1}, \mathbf{X}_{2}, \ldots, \mathbf{X}_{\mathrm{n}}\right)=\mathrm{E}\left(\mathbf{X}_{1} \mathbf{X}_{2} \ldots \mathbf{X}_{\mathrm{n}}\right)-$ $\mathrm{E}\left(\mathbf{X}_{1}\right) \mathrm{E}\left(\mathbf{X}_{2}\right) \ldots \mathrm{E}\left(\mathbf{X}_{\mathrm{n}}\right)$. By definition, a sequence of maps that is independent results in a zero covariance. Covariance scores greater than zero do not have a statistically defined meaning, but may be used descriptively for a unit's tendency to repeatedly discharge in the same location on the maze during a series of trials. Examination of the frequency distribution of the covariance scores of complex spike cells showed that a subset of the scores clustered around zero and that the remaining scores were widely distributed in the positive range. An arctan transform was applied to normalize the distribution, and a correspondence between the reliability and normalized covariance scores was confirmed by a significant correlation between the variables $(r=0.38, p<0.001)$. Correlation analysis also revealed that specificity correlated with information content $(r=$ $0.31, p<0.01)$ and that information content and the covariance index were related to the average rate of complex spike cells $(r=-0.64, p<$ 0.001 and $r=0.40, p<0.001$, respectively). To ensure that comparisons of place field properties were not confounded by firing rate, group differences in information content and covariance index were subjected to analysis of covariance with the average discharge rate as a covariate. Fields in novel and familiar environments were compared by first visually inspecting whether location-dependent activity was observed in each of the two environments. The fields were classified as "unique" if only present in one of the two rooms. If fields were identified in both environments, they were further analyzed by rotating the rate maps in $90^{\circ}$ steps to examine whether they overlapped with respect to the quadratic geometry of the recording room. If overlapping in one of the four positions, the fields were categorized as "retained" or, alternatively, if no overlap could be seen, as "shifted."

Statistical analysis. (1) Correlation coefficients were calculated to compare behavioral performance with lesion size. The average number of working memory errors for all trials during the $7 \mathrm{~d}$ of postoperative retraining was used as the index for behavioral performance. Lesion size was determined as described below. (2) Correlation coefficients were also calculated for each recording session comparing the number of working memory errors with the average place field parameters of the session (rate, specificity, information content, reliability, covariance index). (3) Independent $t$ tests were used for comparing continuous variables between the control and lesioned group. (4) Place field parameters of individual units were analyzed using regression analysis. The behavioral performance index and lesion size of each animal were entered as
Table 1. Number of complex spike cells recorded from each individual

\begin{tabular}{lllll} 
CONTROL & & & MSX & \\
\cline { 1 - 2 } $\begin{array}{l}\text { Animal } \\
\text { identification }\end{array}$ & $\begin{array}{l}\text { Complex } \\
\text { spike cells }\end{array}$ & & $\begin{array}{l}\text { Animal } \\
\text { identification }\end{array}$ & $\begin{array}{c}\text { Complex } \\
\text { spike cells }\end{array}$ \\
\hline C1 & 2 & & X1 & 4 \\
C2 & 7 & & X2 & 22 \\
C3 & 17 & & X3 & 25 \\
C4 & 10 & & X4 & 13 \\
C5 & 10 & & X5 & 12 \\
C6 & 25 & & \\
Total & 71 & & 76
\end{tabular}

$\overline{\text { CONTROL, Subjects received a vehicle injection; MSX, subjects received a quino- }}$ linic acid injection in the medial septal nucleus.

independent variables, and place field parameters were entered as dependent variables. The variability between units of each animal contributed to the error variance. Because regression analysis required that individual units of each animal be considered for statistical analysis, additional statistical tests of place field parameters were also performed for individual units rather than individual animals. Table 1 shows that four of six control and four of five lesioned animals contributed at least 10 units to the total number of observations, assuring that the results are not attributable to the contribution of a limited number of individuals. (5) The proportion of theta-modulated interneurons, the proportion of units with place fields, and the response pattern of the fields in novel and familiar environments were compared using $\chi^{2}$ tests. (6) The dark effects on place fields were tested by using ANOVA with lesion group and testing condition as independent variables.

Histology. At the end of the experiments the animals were given an overdose of pentobarbital and perfused intracardially with saline followed by a $10 \%$ formalin solution. The brains were immersed in a $30 \%$ sucrose/formalin solution for at least $24 \mathrm{hr}$. Sections $(40 \mu \mathrm{m})$ were taken and stained with cresyl violet. The histological sections were used to identify the electrode tracts and to quantify the septal lesions. Septal lesions were analyzed using NIH Image by measuring the volume of the septal area from the level of the island of Calleja to the level of the decussation of the anterior commissure (Stewart and Vanderwolf, 1987; Leung et al., 1994). The measured septal area was delimited dorsally by the corpus callosum, laterally by the ventricles, and ventrally by a horizontal line between the ventralmost extent of the ventricles. The striatal area laterally adjacent to the septum was measured in identical sections, and septal volume was expressed as percentage of striatal volume to correct for variability in individual brain size as well as tissue shrinkage during histological processing.

\section{RESULTS}

\section{Behavioral performance and histology}

Behavioral performance on the radial arm maze was not different preoperatively (Fig. $1 A)(\mathrm{df}=11, t=0.35, \mathrm{NS})$, but the number of working memory errors selectively increased in lesioned compared with control animals during postsurgical retraining (Fig. $1 B)(\mathrm{df}=11, t=-3.87, p<0.01)$. Control animals continued to improve, but working memory errors transiently increased (Fig. $1 B, C)$ and then decreased in the lesion group (Fig. 1D) $(\mathrm{df}=9$, $t=-1.63$, NS). The pronounced initial spatial working memory impairment is characteristic for hippocampal lesions, fimbriafornix lesions, electrolytic septal lesions, and septal inactivation (Winson, 1978; Mizumori et al., 1989; M'Harzi and Jarrard, 1992; Whishaw and Jarrard, 1995).

The volume of the septal area appeared reduced in lesioned animals (Fig. 2A) compared with control animals (Fig. 2B), and statistical analysis confirmed the decreased septal volume after excitotoxic amino acid injections (Fig. $2 C)(\mathrm{df}=11, t=4.81, p<$ $0.001)$. Septal volume correlated with the average number of postoperative working memory errors in the experimental group 

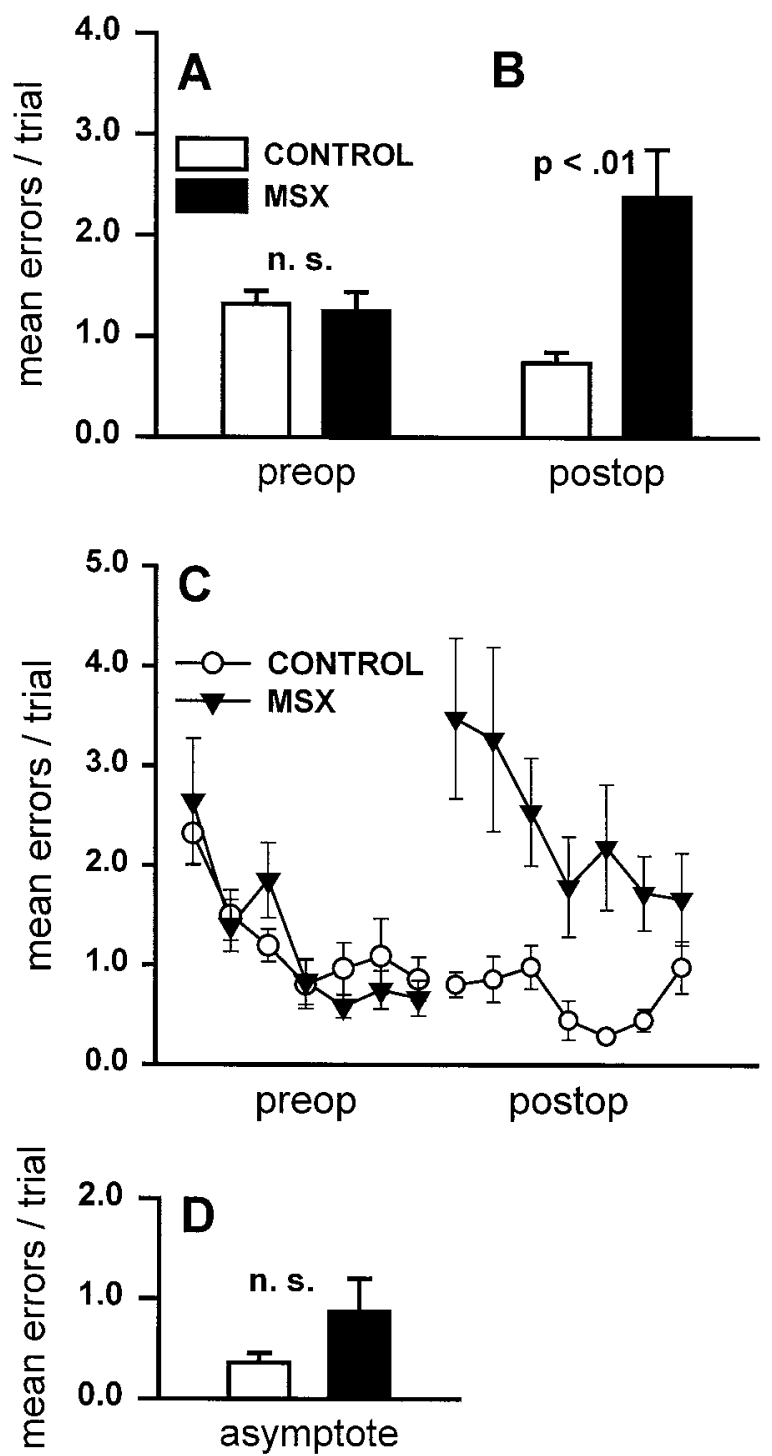

Figure 1. Behavioral effects of excitotoxic septal lesions. $A$, Preoperative memory performance was not different among animals that were assigned to the control and lesion group as indicated by the average number of working memory errors per trial $( \pm$ SEM) during the initial $7 \mathrm{~d}$ of training. $B$, The average number of working memory errors per trial $( \pm \mathrm{SEM})$ during $7 \mathrm{~d}$ of postoperative retraining was higher in lesioned than in control animals. $C$, The average number of working memory errors per trial $( \pm$ SEM) for each day of preoperative and postoperative training is shown. Initial preoperative acquisition of the working memory task was similar for control and lesioned animals. Lesioned animals showed a transient increase in working memory errors during postoperative retraining. $D$, Lesioned and control animals reached similar levels of asymptote performance during the recording sessions. The lesioned animals showed a small but insignificant increase in errors compared with controls. The performance during all recording sessions was averaged for each animal, and an independent $t$ test was used for the statistical comparison. Control (CONTROL) subjects received a vehicle injection; lesioned (MSX) subjects received a quinolinic acid injection in the medial septal nucleus.

(Fig. $2 D)(n=6, r=0.821, p<0.05)$, but was unrelated to postsurgical behavioral performance in control animals (Fig. 2D) ( $n=7, r=-0.432$, NS).

\section{Hippocampal physiology: consequences of septal lesions}

Hippocampal complex spike cells $(n=147)$ and interneurons $(n=46)$ were recorded from six control and five lesioned animals.
Recordings were not obtained from one control and one lesioned animal for which complete behavioral and histological data were available. The apparent overrepresentation of interneurons compared with anatomically identified populations presumably resulted from advancing the electrodes through hippocampal layers outside of the stratum pyramidale and the presence of numerous nonspiking pyramidal cells in the stratum pyramidale (Thompson and Best, 1989). Matching the recordings of complex spike cells to histologically identified electrode tracts revealed that 104 units were recorded from CA1, and 43 from CA3 (Table 2). In control animals, 7 complex spike cells were recorded in baseline sessions $(n=2)$, and 64 cells were recorded in sessions $(n=18)$ of 15 trials, which included testing in darkness. In lesioned animals, 28 complex spike cells were recorded in baseline sessions $(n=8)$, and 48 cells were recorded in sessions $(n=23)$ of 15 trials.

\section{Complex spike cells}

For analyzing the entire population of complex spike cells recorded in control and lesioned animals, data from the initial five trials in light were combined with data from sessions with baseline trials only. Two-way analysis of covariance with rate as a covariate did not reveal significant interactions between recording site and lesion group for any of the field parameters. Therefore data from CA1 and CA3 were combined for statistical comparisons. Spike amplitudes of complex spike cells recorded from control and lesioned animals were not different (control $155.3 \pm 5.9 \mu \mathrm{V}$, lesioned $150.6 \pm 6.5 \mu \mathrm{V} ; \mathrm{df}=144, t=0.53, \mathrm{NS}$ ), and quantitative comparisons of scores for field parameters did not reveal significant differences for specificity (log transform) (Fig. $3 A)(\mathrm{df}=$ $142, t=-0.44$, NS), information content (Fig. $3 B)(\mathrm{df}=144, t=$ $-1.39, \mathrm{NS})$, and reliability (Fig. $3 C)(\mathrm{df}=144, t=0.67, \mathrm{NS})$. The covariance index was significantly decreased in lesioned compared with control animals (Fig. $3 D)(\mathrm{df}=141, t=2.73, p<$ 0.01 ), suggesting that spatial correlates of hippocampal complex spike cells were not consistently maintained when septal function was compromised. The effect was controlled for rate by confirming that the average firing rates for cells of control animals were not different from those of lesioned animals $(0.72 \pm 0.09 \mathrm{~Hz}$ vs $0.61 \pm 0.11 \mathrm{~Hz}$; df $=146, t=0.77, \mathrm{NS})$ and by testing the effect of the septal lesion by using analysis of covariance with rate as a covariate. Analysis of covariance revealed a significant group effect $\left(F_{(1,141)}=4.87, p<0.05\right)$ in addition to confirming the correlation between covariance index and rate $\left(F_{(1,141)}=22.73\right.$, $p<0.001)$. The significant difference in the covariance index in the absence of a difference in reliability may reflect the lower sensitivity of the latter measurement. The reliability score only indicates changes to a different arm, whereas the covariance index is also sensitive to variations within maze arms. In addition, the reliability score only measures consistent location-dependent activity when the units have a well defined place field, which is not the case for a subset of the complex spike cells (see below).

\section{Proportion of units with place fields}

When selecting for place fields by using similar criteria as in a previous study (Mizumori et al., 1992b), i.e., by using a specificity score of $\geq 2.0$ and a reliability score of $\geq 37.5 \%, 70.4 \%$ of the units of control animals were found to have spatial correlates in control animals, whereas only $52.6 \%$ of the complex spike cells fulfilled the criteria for spatial correlates in lesioned animals ( $\mathrm{df}=1$, $\left.\chi^{2}=4.89, p<0.05\right)$. The same trend was independently observed for control/lesion units in CA1 $(69.4 \% / 57.1 \%)$ and CA3 $(77.8 \% / 47.1 \%)$ but did not reach significance in either 

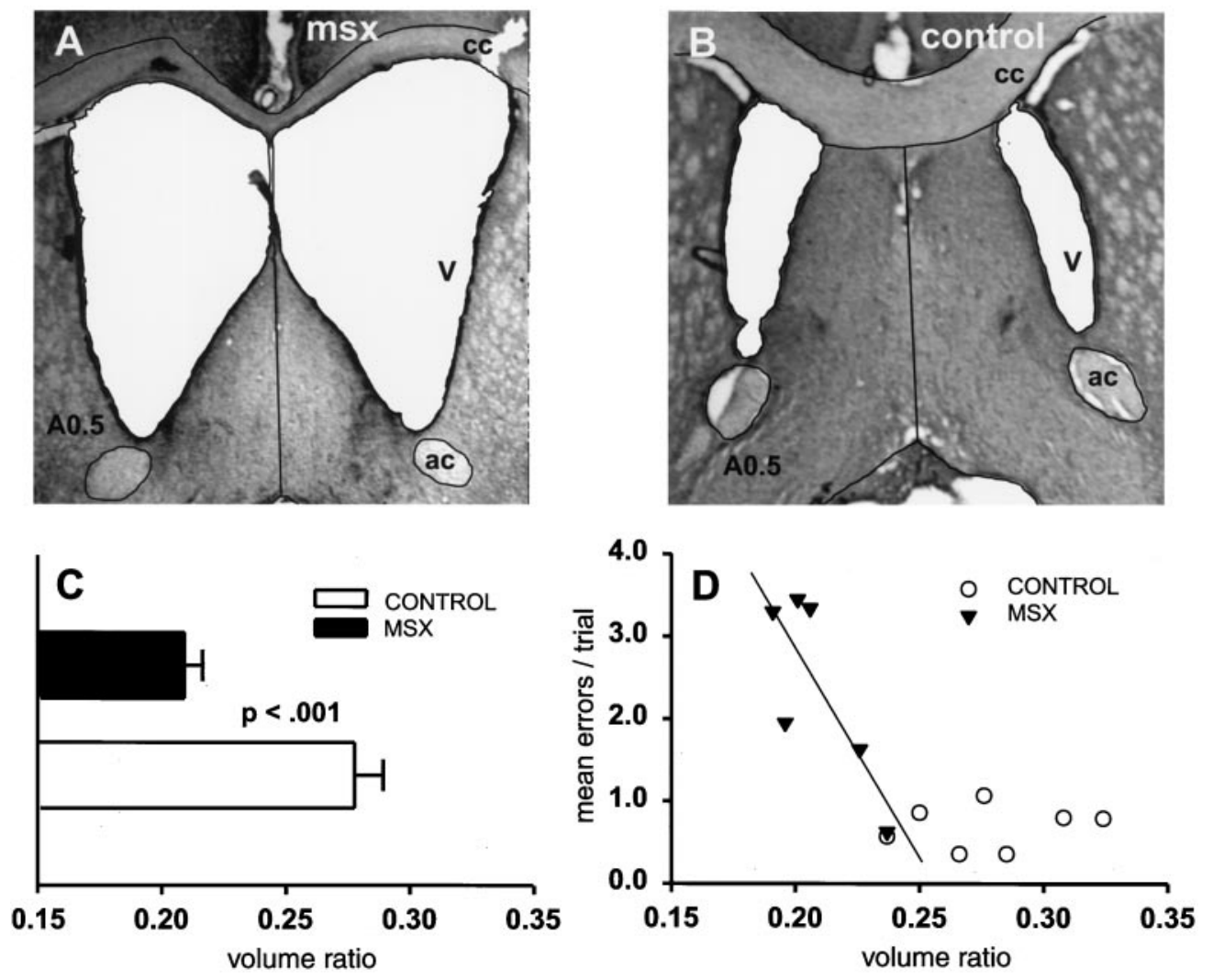

Figure 2. Neurodegeneration in the septal nuclei after excitotoxic lesions. Septal volume was quantified as described in Stewart and Vanderwolf (1987) by measuring the area between the corpus callosum, the lateral ventricles, and a horizontal line between the ventralmost extent of the ventricles. $A$, $B$, Coronal sections at the level of the septal area $(0.5 \mathrm{~mm}$ anterior to bregma) in a lesioned and control animal. Neurodegeneration after excitotoxic lesions resulted in a bottleneck-shaped appearance of the septal nuclei, which was more pronounced for cases with more severe damage. $C$, The average volume ratio $( \pm$ SEM) was significantly smaller in lesioned compared with control animals. Septal volume is represented as the ratio of septal compared with striatal volume. $D$, The volume ratio correlated with the mean working memory errors per trial in the lesioned group but not in the control group. $a c$, Anterior commissure; $c c$, corpus callosum; $V$, lateral ventricle.
Table 2. Hippocampal single units were classified according to their location along the electrode tract and physiological criteria

\begin{tabular}{llllc} 
& CA1 & CA3/hilus & Interneurons & Total \\
\hline CONTROL $(n=6)$ & 62 & 9 & 19 & 90 \\
$\operatorname{MSX}(n=5)$ & 42 & 34 & 27 & 103
\end{tabular}

The number of subjects is indicated in parentheses.

area separately, probably because of the smaller number of observations for each case.

\section{Correlation analysis}

When induced by neurotoxic agents, neuronal cell death in the septal area continues for several days (Stewart and Vanderwolf, 1987), and the initial loss of cell populations may result in additional structural changes attributable to compensatory processes (Cotman and Nieto-Sampredo, 1982). It has been shown, however, that the decrease in theta power after excitotoxic lesions is stable as early as $3 \mathrm{~d}$ after the lesion (Leung et al., 1994), and postsurgical retraining in the present study did not begin until $>10 \mathrm{~d}$ after the neurotoxin injection. There were no correlations between the working memory errors during a recording session and any of the measurements of location-dependent properties of the complex spike cells $(\mathrm{df}=51$; all $p$ values $>0.4)$. Attempts were made to correlate the behavioral performance during the acquisition phase of the spatial memory task with the data on place fields. Although the fields were not recorded along with the impaired behavioral performance, the initial performance during acquisition may measure the functional status of the septohippocampal system. In addition, lesion size was correlated with the memory performance during postsurgical acquisition of the memory task (see above).
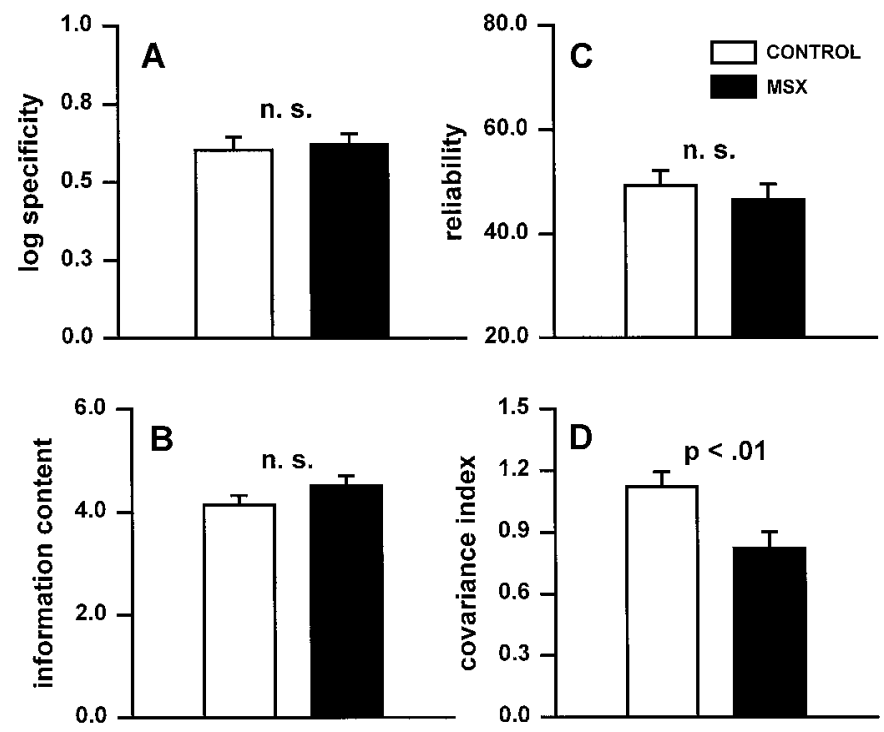

Figure 3. Location-dependent discharge of complex spike cells. Location specificity was unaffected in the lesioned group as indicated by the specificity score $(A)$ and information content $(B)$. The reliability score of complex spike cells $(C)$ was not different between control and lesioned animals, but the covariance index $(D)$, which is a more sensitive measurement for reliable location-dependent discharge (see Materials and Methods), revealed an increase in the between-trial variability for complex spike cells recorded from lesioned compared with control animals.

Regression analysis revealed that both behavioral performance and septal volume were related to the covariance index (Fig. 4) $\left(F_{(1,142)}=17.97, p<0.001 ; F_{(1,142)}=6.78, p<0.05\right.$, respectively $)$, but no relation to either reliability $\left(F_{(1,145)}=0.17, \mathrm{NS} ; F_{(1,145)}=\right.$ 
A

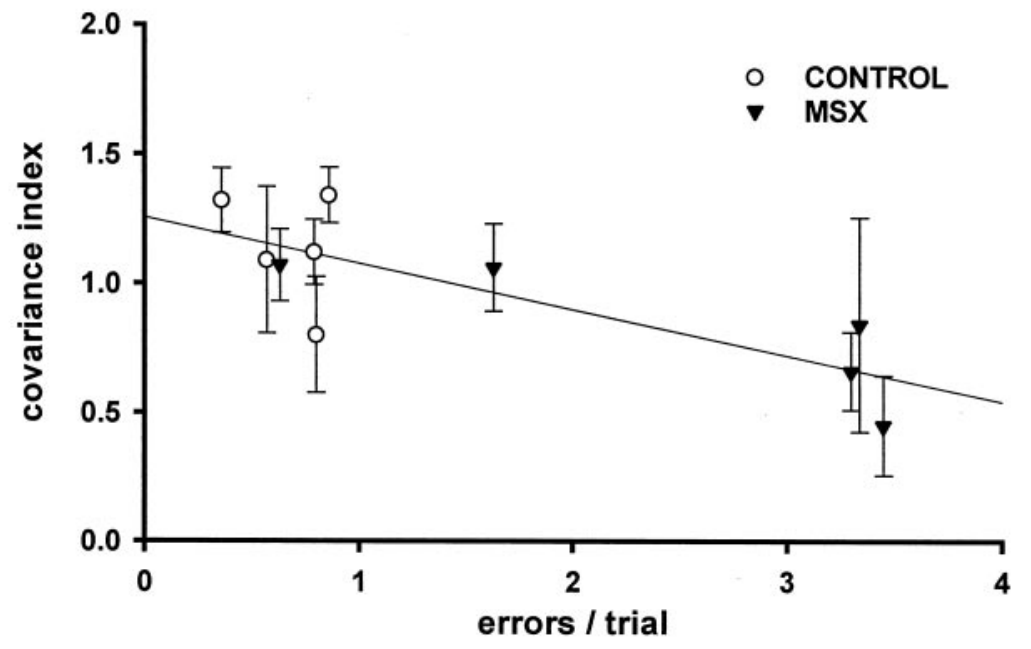

B
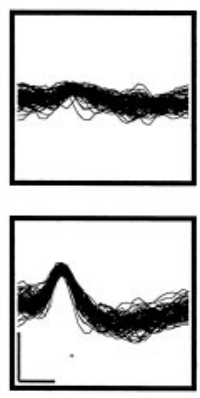

MSX

Figure 4. Less reliable location-dependent activity of hippocampal complex spike cells correlated with the working memory deficit during postoperative retraining. $A$, The average covariance index $( \pm \mathrm{SEM})$ for complex spike cells that were recorded from individual subjects is shown. $B$, Stereotrode waveforms and rate maps for a complex spike cell recorded from a lesioned animal. The traces in the top and bottom box represent the waveforms of individual action potentials on each of the two stereotrode wires. Rate maps for two of five individual trials are shown. The size of the circle corresponds to the rate in each location of a 64 by 64 grid, and vectors represent the direction of movement during single-unit activity. Lower covariance indices resulted from inconsistent location-dependent activity during a sequence of trials. $C$, Waveforms and rate maps for a complex spike cell recorded from a control animal. Consistent location-dependent activity during individual trials resulted in higher covariance scores. Calibration bars: $B, 50 \mu \mathrm{V}, 250 \mu \mathrm{sec} ; C, 100 \mu \mathrm{V}$, $250 \mu \mathrm{sec}$.

\section{C}
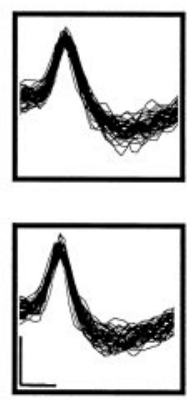
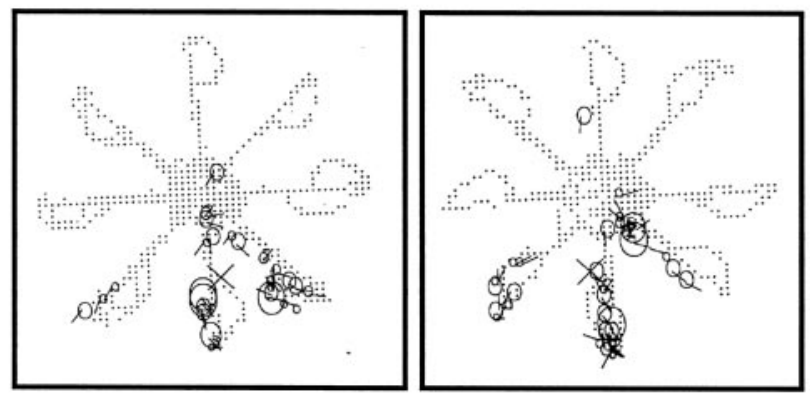

CONTROL
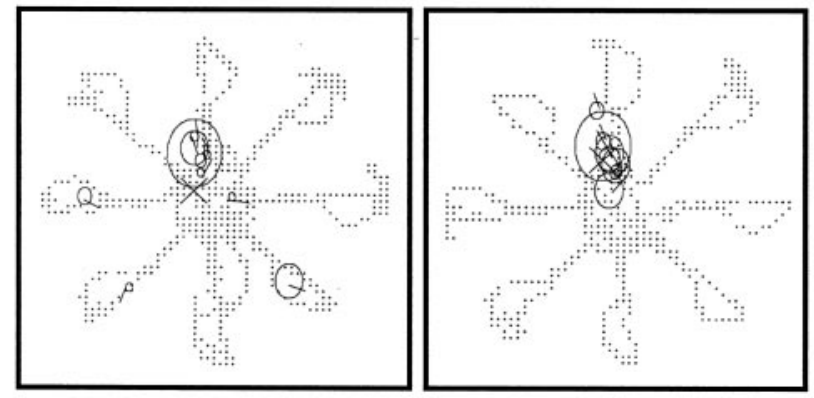

$0.004, \mathrm{NS})$ or average rate $\left(F_{(1,146)}=2.39, \mathrm{NS} ; F_{(1,146)}=0.76, \mathrm{NS}\right)$ was found. The correlation between behavioral performance, septal volume, and covariance index suggests that the septal neurons, which degenerate after the lesion, contribute to consistent location-dependent discharge of complex spike cells in normal animals as well as the acquisition of the spatial working memory task.

\section{Dark effects}

The contribution of visual cues to the activity of hippocampal units was tested by including dark trials in the recording sessions. The number of fields observed in only one of the conditions (light or dark) was similar for control and lesioned animals (42.2 and $41.7 \%$, respectively). In addition, changes of the fields between conditions were analyzed. In control animals, $43.8 \%$ of the complex spike cells had fields in both conditions, and one-third of these $(10 / 28)$ had fields in identical locations. In lesioned animals, $29.2 \%$ of the cells had fields in both conditions, and 3 of 11 fields were in identical locations. When the pattern of organization (identical, different, or unique to one condition) was compared between conditions, significant differences in response to altered lighting conditions were not seen (Table 3 ).

Due to the smaller number of dark fields relative to light fields in the control group (Table 3), the proportion of fields that were observed in the absence of visual cues was not different from lesioned animals (58.5 and $47.9 \%$, respectively, NS). More place fields were seen in controls compared with lesioned animals during the baseline light condition (see above) and when the 
Table 3. Spatial correlates during baseline conditions and in the absence of ambient illumination

\begin{tabular}{lllll} 
& $\begin{array}{l}\text { Identical } \\
(\%)\end{array}$ & $\begin{array}{l}\text { Different } \\
(\%)\end{array}$ & $\begin{array}{l}\text { Unique (light/ } \\
\text { dark only) }(\%)\end{array}$ & $\begin{array}{l}\text { No field } \\
(\%)\end{array}$ \\
\hline CONTROL & & & & \\
$\%$ total $(n=64)$ & 15.6 & 28.1 & $42.2(28.1 / 14.1)$ & 14.1 \\
$\quad \%$ fields $(n=55)$ & 18.2 & 32.7 & 49.1 & \\
MSX & & & & \\
$\%$ total $(n=48)$ & 6.3 & 22.9 & $41.7(22.9 / 18.8)$ & 29.2 \\
$\%$ fields $(n=34)$ & 8.8 & 32.4 & 58.8 & \\
\hline
\end{tabular}

Fields are more frequently seen in control than in lesioned animals. This Table therefore includes the proportion of fields in comparison to the total number of units and in comparison to the number of fields in the baseline condition. The total number of complex spike cells that were recorded in both conditions (total) and the number of complex spike cells that had place fields in any of the conditions (fields) are indicated in parentheses. Identical, Fields were observed on the same maze arm in the baseline light condition and in darkness. Different, The peak activity of the field was located on different maze arms for each of the conditions. Unique, Fields were only observed in either the light or the dark condition. $\mathrm{A} \chi^{2}$ test comparing the fields of the control and lesioned group in the three conditions (identical, different, unique) did not reveal a significant difference in responses across conditions ( $\mathrm{df}=2$, $\left.\chi^{2}=1.79, p>0.4\right)$.

lighting was restored $\left(80.3\right.$ and $53.1 \%$, respectively; $\mathrm{df}=1, \chi^{2}=$ $9.70, p<0.01)$. Changes in the place fields in darkness were also partially reflected in the quantitative measurements of the fields properties (Fig. 5). Specificity, reliability, and covariance index changed with the illumination $\left(F_{(2,106)}=18.47, p<0.001\right.$; $F_{(2,109)}=7.48, p<0.01 ; F_{(2,108)}=3.80, p<0.05$, respectively $)$, but rate and information content remained unaffected $\left(F_{(1,111)}=\right.$ 0.16 , NS, $F_{(1,109)}=0.00$, NS, respectively). In addition, a significant effect of the septal lesion on both reliability and covariance index was revealed $\left(F_{(1,109)}=4.23, p<0.05 ; F_{(1,108)}=5.10, p<\right.$ 0.05 , respectively). Interactions were not observed for any of the measurements (all $p$ values $>0.1$ ). Beginning the recording session in darkness resulted in effects (data not shown) that resembled those that were seen when dark trials were introduced after the light trials, indicating that the initial absence of visual cues does not further disrupt the fields of control and lesioned subjects in the familiar environment.

\section{Novel environment effects}

Experience with novel environments results in a reorganization of the hippocampal representations for space (O'Keefe and Conway, 1978; Kubie and Ranck, 1983; Muller and Kubie, 1987; Thompson and Best, 1989; Wilson and McNaughton, 1993). A subpopulation of complex spike cells changes immediately in response to novel visual cues and a different subset of cells develops fields over a time course of at least several minute. Stable recordings throughout the test period were obtained from two control and three lesioned animals. Testing of place fields in the control animals ( $n=8$ cells) indicated that the majority of fields in the control group was different across environments $(n=$ $7 / 8$ ); that is, cells continued to show fields in the novel environment, but the spatial distribution of the fields differed (Fig. 6A). In contrast, the pattern of responses by place cells from lesioned animals ( $n=9$ cells) was comparatively limited. The fields of only two of the nine complex spike cells were redistributed, whereas the remaining place fields tended to either be identical across environments $(n=3 / 9)$ (Fig. $6 B)$ or present in one or the other environment $(n=4 / 9)$. Identical place fields in the two environments were seen in lesioned animals despite the overall inconsistency in location-dependent activity in the familiar environment (see above). A $\chi^{2}$ test indicated that the reorganization between environments is different for the control and lesion group (Table 4) $\left(\mathrm{df}=2, \chi^{2}=7.75, p<0.05\right)$.

\section{Interneurons}

Average spike amplitudes and rates of interneurons in the control and lesioned group were not different (spike amplitudes: control $99.3 \pm 7.2 \mu \mathrm{V}$, lesioned 134.6 $\pm 13.8 \mu \mathrm{V}$, df $=43, t=-1.97, \mathrm{NS}$; rates: $\mathrm{df}=43, t=0.68$, NS) (Fig. $7 A$ ). Autocorrelation histograms revealed that $94.7 \%(18 / 19)$ of the interneurons in the control group showed peaks in the theta range, and only $51.9 \%(14 / 27)$ of the units in the lesioned group showed evidence of rhythmicity (Fig. $7 B$, inset, $C, D)\left(\mathrm{df}=1, \chi^{2}=9.69, p<0.01\right)$. Comparing the peaks of the autocorrelation histograms of theta-modulated units did not reveal a difference in the preferred discharge frequency (Fig. $7 B)(\mathrm{df}=30, t=1.53, \mathrm{NS})$. The decreased probability of rhythmic activity without changes in theta frequency are consistent with EEG data, which have shown that theta amplitude, not frequency, is predominantly affected after excitotoxic septal lesions (Bland and Bland, 1986; Leung et al., 1994).

\section{DISCUSSION}

Behavioral deficiency during the acquisition phase of a spatial memory task correlated with reduced septal volume after excitotoxic lesions. The increased number of working memory errors as well as the decreased septal volume were related to less reliable location-dependent activity of hippocampal complex spike cells, although location specificity was unchanged. A smaller proportion of complex spike cells with place fields was observed in lesioned compared with control animals, and testing of the spatial correlates of place cells in the absence of ambient illumination showed that the number of fields decreased in control but not lesioned animals. Conversely, a trend for a lesser degree of visual context dependence for the complex spike cells of lesioned animals was seen during testing in a new environment. A contribution of the interneuron population to the functional changes in hippocampal physiology is suggested by a significantly lower proportion of theta-modulated interneurons in lesioned compared with control animals.

\section{Septal lesion effects on behavioral performance and hippocampal physiology}

Spatial working memory deficits are consistently seen after nonspecific septal lesions (Winson, 1978; Hepler et al., 1985; Hagan et al., 1988) and to a lesser extent after selective cholinergic lesions of medial septal projection neurons (Shen et al., 1996; Walsh et al., 1996; McMahan et al., 1997). Consistent with this trend, in the present study lesion size correlated with the memory deficit during reacquisition of the spatial memory task. These data suggest that increased septal neurodegeneration results in the expression of more severe working memory impairments. In addition, less proficient behavioral performance during the reacquisition phase of a spatial task correlated with a decreased consistency in location-dependent single-unit activity. The single units were recorded, however, after the spatial working memory impairment was measured, at the time when the behavioral performance of lesioned animals was similar to controls. Comparable performance during the recording sessions assured that our results were not confounded by different behavioral patterns. Because the memory impairments that were initially observed were sufficiently compensated for, the pattern of hippocampal singleunit activity may be a consequence of reacquiring the task by using different strategies than those used by control animals, 
log specificity

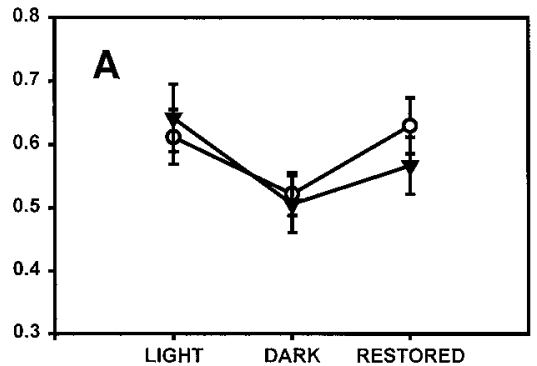

information content

Figure 5. Location-dependent activity of complex spike cells during sessions that included baseline trials (LIGHT), trials in darkness (DARK), and trials with the lights restored (RESTORED). An effect of the septal lesion was not seen for specificity $(A)$ and information content $(B)$, but the overall reliability $(C)$ and covariance index $(D)$ were significantly higher for the control compared with the lesion group. A dark effect was observed for specificity, reliability, and covariance, but not for the information content. Interactions were not observed for any of the place field parameters.

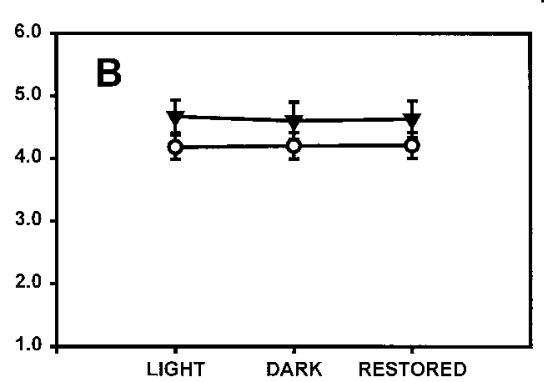

LIGHT DARK RESTORED reliability
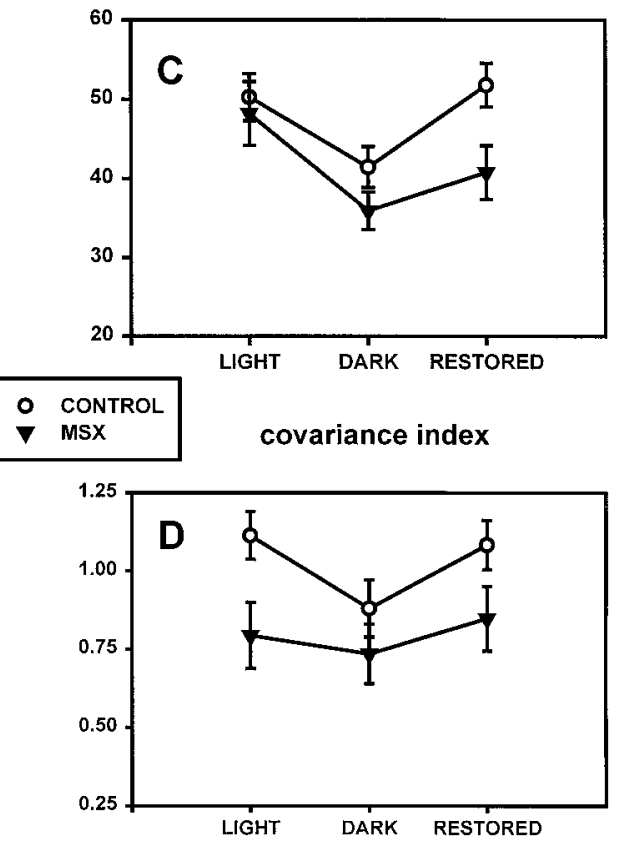

\section{A CONTROL}

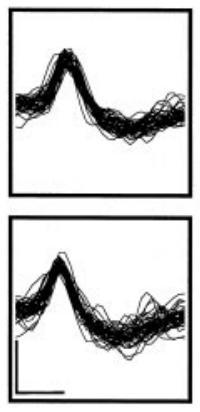

FAMILIAR ENVIRONMENT

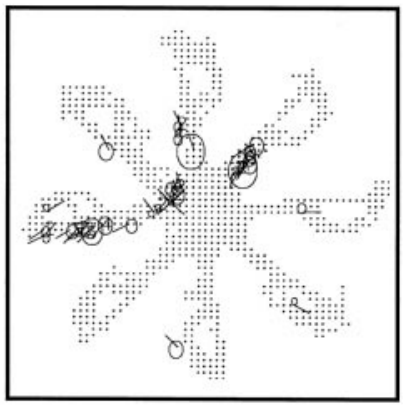

showed activity during inbound movement in the familiar room and activity during outbound movement in the novel room. Testing in a different environment resulted in place fields with a different spatial distribution in the majority of complex spike cells $(n=7 / 8)$ of control animals. $B$, Waveforms and rate maps for a complex spike cell recorded from a lesioned animal in the familiar and novel environment. The example illustrates the response of a subset of complex spike cells $(n=3 / 9)$ that showed similar fields in both environments. Others $(n=$ 4/9) were present in either one or the other environment, and only two of nine units of lesioned animals showed the redistribution that was the typical response for the units of control animals. Calibration bars: $B, 80 \mu \mathrm{V}$, $250 \mu \mathrm{sec} ; C, 100 \mu \mathrm{V}, 250 \mu \mathrm{sec}$.

\section{B MSX}

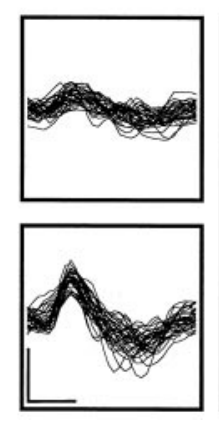

FAMILIAR ENVIRONMENT



NOVEL ENVIRONMENT
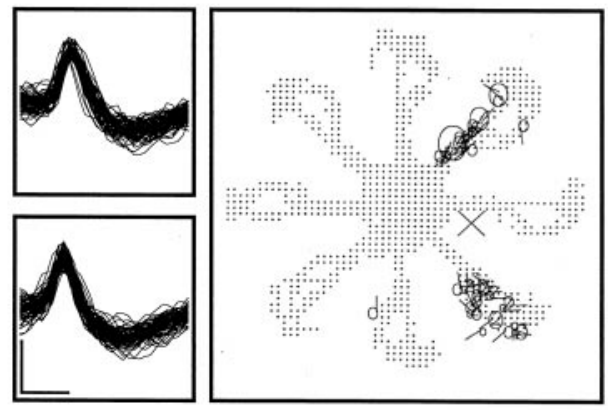

NOVEL ENVIRONMENT
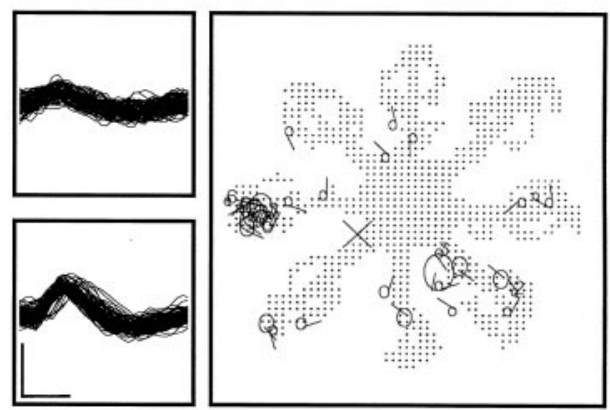

which could then result in altered hippocampal information processing. The prominent direct anatomical connections between septum and hippocampus would suggest, however, that hippocampal function is impaired as a direct result of the septal lesion and that brain structures that are less affected by the septal lesion can accommodate the apparent behavioral compensation.

The lesion effects on hippocampal single-unit activity in the present study were relatively moderate compared with those that were described after fimbria-fornix transsections and septal inactivation. In contrast to fimbria-fornix lesions and septal inactivation, theta activity is present after excitotoxic lesions of the septal nuclei (Stewart and Vanderwolf, 1987; Leung et al., 1994), and cholinergic neurotransmission is partially preserved (Hepler et al., 1985; Hagan et al., 1988; Brandner and Schenk, 1998). Projections from hypothalamic nuclei contribute to synchronized population activity in the hippocampal formation (Vertes and 
Table 4. Comparison of place fields in the familiar and novel environment

\begin{tabular}{llll} 
& Retained & Shifted & Unique \\
\hline CONTROL $(n=8)$ & 1 & 7 & 0 \\
$\operatorname{MSX}(n=9)$ & 3 & 2 & 4
\end{tabular}

Retained, Field in the same location on the maze in the familiar and novel room. Shifted, Fields in different locations in the familiar and novel room. Unique, Field appeared only in the familiar or the novel room.

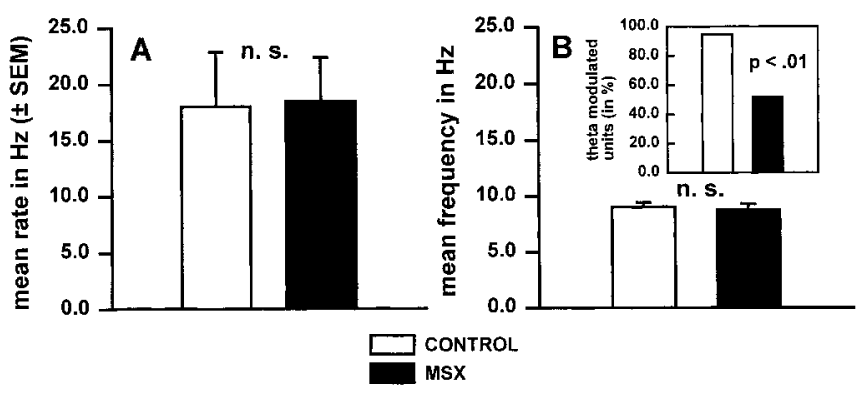

C

CONTROL

D

Msx


Figure 7. Lesion effects on hippocampal interneurons. $A$, The mean discharge rate in $\mathrm{Hz}( \pm \mathrm{SEM})$ for interneurons of lesioned animals was not different from that of controls. $B$, The theta frequency of individual interneurons was estimated by measuring the mode of the peak in the 50-200 msec range in the autocorrelation histogram. The inverse of the mode was considered the predominant theta frequency of the interneuron. The mode was calculated from the subpopulation of interneurons that showed theta modulation, which was different for the control and lesioned group (as shown in the inset). $C$, Autocorrelation histogram (in arbitrary units) of a theta-modulated interneuron that was recorded in a control animal. $D$, Autocorrelation histogram of an interneuron recorded in a lesioned animal. Theta modulation was absent in $48.1 \%$ of the interneurons that were recorded along electrode tracts that also yielded recordings from complex spike cells.

Kocsis, 1997) and, along with the remaining cholinergic projections from the medial septum, may result in partially preserved population activity. The average discharge rate of complex spike cells was not altered in animals with excitotoxic lesions but either increased or decreased after fimbria-fornix lesions (Miller and Best, 1980; Shapiro et al., 1989). Miller and Best (1980) also reported a decreased signal-to-noise ratio of place field activity. The specificity and information content measurements used here would be sensitive to these changes, but lower scores were not observed after the excitotoxic lesion. Consistent findings for both types of lesion studies include decreased reliability scores for place fields of animals with fimbria-fornix (Shapiro et al., 1989) and excitotoxic lesions. In addition, when criteria about reliability and specificity of place fields are combined, a decreased proportion of complex spike cells with place fields was reported for the fornix-transsected animals (Miller and Best, 1980), a result that is also seen with the excitotoxic lesion in the present study. An entirely different pattern of responses than with permanent lesions is observed when place fields are tested while the medial septal nucleus is transiently inactivated. Temporary inactivation of the medial septal area results in a decreased discharge rate of complex spike cells in the CA3/hilar area and the absence of place fields in this subregions of hippocampus. CA1 fields are unaffected by the same manipulation, indicating that their pattern of activity can be reestablished when the contribution from CA3 neurons is diminished (Mizumori et al., 1989). The differences in hippocampal physiology after permanent and temporary deficits in septal functions could be a consequence of compensatory changes in the relative strength of intrahippocampal inhibitory and excitatory connections.

\section{Relative contribution of the septal area and hippocampus to spatial learning}

The combined behavioral and physiological data suggest that functional deficits in hippocampus result in memory deficits or, alternatively, that hippocampal physiology is inconsequential for behavioral performance and a mere indicator of septal dysfunction. The behavioral deficit may result, for example, from a direct septal contribution to working memory using projections from the lateral nuclei to subcortical areas. In the absence of substantial evidence for a role of descending septal projections in spatial memory performance, we argue that the effects of lesions on behavior are likely mediated by direct septal contributions to hippocampal function or medial septal projections to cortical areas (e.g., entorhinal cortex) that are connected to hippocampus. The lateral septal nuclei could indirectly modulate hippocampal function by either sparse direct or more prominent indirect projections to the medial septum (Jakab and Leranth, 1995; Risold and Swanson, 1997).

The medial septal nuclei have been implicated in working memory processes rather than in contributing directly to the spatial representation of the environment (Givens and Olton, 1990; Givens, 1996). Recent studies have also found location and directional correlates in the lateral and medial septal nuclei (Ono et al., 1997; King et al., 1998). Single units in the septum could thus provide information to hippocampus that may regulate when and where increased flexibility is required. We hypothesize that septal lesions result in a suppression of transient increases in the flexibility of hippocampal representations, which may be necessary to establish context dependency as well as to support working memory.

\section{Reorganization in response to altered sensory cues}

Changing the lighting condition does not result in new and independent hippocampal place representations in normal rats, i.e., the representations for the light and dark conditions partially overlap. Differences between the control and lesion group therefore should not be readily observed with such relatively minor changes in environmental conditions. Testing without ambient illumination revealed a similar response pattern of control and lesioned animals. Conversely, testing place fields in new environments normally results in a complete reorganization of the hippocampal representation in controls, and the fields of lesioned animals did not reorganize as readily to the altered context. The latter result was recently confirmed in a preliminary report showing that place fields are less likely to be reorganized in novel contexts after selective septal cholinergic lesions (Ikonen et al., 1998).

Fimbria-fornix lesions also modify place field responses to changes in the sensory environment. Disrupting the constellation of visual and intramaze cues resulted in disintegrated fields or 
fields that were controlled only by intramaze cues (Miller and Best, 1980; Shapiro et al., 1989). Although the earlier results can be interpreted as an increased dependence of the place fields of lesioned animals on local cues, the present transfer tests to a novel environment would not be consistent with this interpretation. Assuming similar contributions to hippocampal dysfunction with different lesion techniques, the combined findings could be interpreted as a deficit in appropriately integrating information from different sensory modalities during periods of new learning. A specific contribution of medial septal cholinergic neurons to the flexible use of hippocampal spatial representations is suggested by the finding that acetylcholine projections are more important for working than reference memory (Torres et al., 1994; Baxter and Gallagher, 1996; Walsh et al., 1996; Shen et al., 1996) and that acetylcholine release prevents already learned information from interfering with new learning (Hasselmo and Bower, 1993).

\section{Relation of the excitotoxic lesion model to aging studies}

Functional changes in the aged hippocampus could primarily be a result of either degenerative processes within the hippocampal formation or compromised basal forebrain projections to hippocampus. Age-related degenerative processes in the septum involve cholinergic and noncholinergic cell populations (de Bilbao et al., 1991; Miettinen et al., 1993; Krzywkowski et al., 1995), which may contribute to, or be more consequential in the presence of, structural and physiological changes in principal neuron and interneuron populations of the aged hippocampus (Barnes, 1979; de Toledo-Morrell and Morrell, 1985; Mizumori et al., 1992a; Shen and Barnes, 1996; Shetty and Turner, 1998). A hippocampal contribution to the spatial learning compromise with advanced age does not result from the loss of pyramidal cells (Rapp and Gallagher, 1996). Rather age-related changes in neural plasticity of existing connections may result in hippocampaldependent memory disturbances. Age-related changes in the hippocampal formation include dendritic reorganization (Flood et al., 1985), loss of inhibitory interneurons (Shetty and Turner, 1998), decreased efficiency of second messenger systems (Colombo et al., 1997), changes in slow wave activity (Markowska et al., 1995), and physiological changes in principal and interneuron populations (Barnes, 1979; de Toledo-Morrell and Morrell, 1985; Mizumori et al., 1992a; Shen and Barnes, 1996; Shetty and Turner, 1998).

Recordings of hippocampal single units in aged freely moving animals have shown that their place fields are less flexible than those of young animals in situations that result in the reorganization of hippocampal fields in younger animals, i.e., during the acquisition of spatial memory tasks, extended exposure to familiar environments, or learning of novel visual cues (Mizumori et al., 1996; Shen et al., 1997; Tanila et al., 1997b). A decreased flexibility of hippocampal representations in testing environments where remapping is expected was also seen in the present study after excitotoxic septal lesions. In contrast, less consistent (i.e., more flexible) location-dependent discharge of hippocampal complex spike cells has been observed when aged animals were repeatedly tested in an identical environment (Barnes et al., 1997). Similarly, we observed less consistent location-dependent activity in individuals with septal lesions during continued exposure to a familiar recording room. Our findings in animals with compromised septal function parallel the seemingly contradictory results in aged individuals across test conditions. The apparent contradiction in memory-impaired aged individuals, however, could be accounted for if their hippocampal representation corresponds to subsets rather than the full extent of sensory information (Rapp, 1998). We suggest that a similar explanation could apply to the septal-lesioned animals.

The consequences of excitotoxic lesions of the septum on hippocampal function provide evidence for a subcortical contribution to cortical information processing in the absence of additional age-related degenerative processes in hippocampus. Behavioral effects after nonselective excitotoxic septal lesions include spatial reference and working memory deficits (Hepler et al., 1985; Hagan et al., 1988), and these deficits are also seen in aged animal populations (Gallagher et al., 1993). In contrast, selective degeneration of cholinergic projection neurons is not sufficient for producing the same range of memory deficits (Berger-Sweeney et al., 1994; Torres et al., 1994; McMahan et al., 1995; Baxter and Gallagher, 1996). The anatomical organization of the septal nuclei differs from other cholinergic cell groups by the additional presence of GABA projection neurons, which selectively project to interneuron populations in the hippocampus (Freund and Antal, 1988). Excitotoxic lesions reduce not only cholinergic neurotransmission but also the number of GABA neurons, in particular in the lateral septal nuclei (Stewart and Vanderwolf, 1987; Leung et al., 1994). The combined loss of different neuron populations in septum may result in memory impairments that are not seen when the cholinergic cell population is selectively targeted. GABA release from subcortical and intrahippocampal sources may serve to disambiguate the input patterns that are received from cortical connections (Wallenstein et al., 1998). Functionally this may serve to select reference frames for interpreting incoming spatial information. The smaller proportion of theta-modulated interneurons in lesioned animals indicates a direct effect of septal projections on interneuron activity and supports the hypothesis that interneuron populations contribute to physiological and behavioral deficits in aged animals (Mizumori et al., 1992a; Shetty and Turner, 1998).

\section{Conclusion}

Although the relation between the changes in hippocampal physiology and the working memory impairment remains to be further clarified, we have shown that neurodegeneration in a subcortical structure can importantly influence spatial information processing by an intact hippocampus. These findings indicate that compromised septal function may, in addition to intrinsic hippocampal degenerative processes, contribute to less flexible information processing in hippocampus with advanced age.

\section{REFERENCES}

Barnes CA (1979) Memory deficits associated with senescence: a neurophysiological and behavioral study in the rat. J Comp Physiol Psychol 931:74-104.

Barnes CA, Suster MS, Shen J, McNaughton BL (1997) Multistability of cognitive maps in the hippocampus of old rats. Nature 338:272-276.

Baxter MG, Gallagher M (1996) Intact spatial learning in both young and aged rats following selective removal of hippocampal cholinergic input. Behav Neurosci 110:460-467.

Berger-Sweeney J, Heckers S, Mesulam M, Wiley RG, Lappi DA, Sharma M (1994) Differential effects on spatial navigation of immunotoxininduced cholinergic lesions of the medial septal area and nucleus basalis magnocellularis. J Neurosci 14:4507-4519. 
Bland SK, Bland BH (1986) Medial septal modulation of hippocampal theta discharges. Brain Res 375:102-116.

Brandner C, Schenk F (1998) Septal lesions impair the acquisition of a cued place navigation task: attentional or memory deficit? Neurobiol Learn Mem 69:106-125.

Colombo PJ, Wetsel WC, Gallagher M (1997) Spatial memory is related to hippocampal subcellular concentrations of calcium-dependent protein kinase C isoforms in young and aged rats. Proc Natl Acad Sci USA 94:14195-14199.

Cotman CW, Nieto-Sampredo M (1982) Brain function, synapse renewal, and plasticity. Annu Rev Psychol 33:371-401.

de Bilbao F, Jazat F, Lamour Y, Senut MC (1991) Age related changes in galanin-immunoreactive cells of the rat medial septal area. J Comp Neurol 313:613-624.

de Toledo-Morrell L, Morrell F (1985) Electrophysiological markers of aging and memory loss in rats. Ann NY Acad Sci 444:296-311.

Flood DG, Buell SJ, Defiore CH, Horwitz GJ, Coleman PD (1985) Age-related dendritic growth in dentate gyrus of human brain is followed by regression in the "oldest old". Brain Res 345:366-368.

Freund TF, Antal M (1988) GABA-containing neurons in the septum control inhibitory interneurons in the hippocampus. Nature 336:170-173.

Gallagher M, Burwell R, Burchinal M (1993) Severity of spatial learning impairment in aging: development of a learning index for performance in the Morris water maze. Behav Neurosci 107:618-626.

Givens B (1996) Behavioral correlates of single units in the medial septal area: the effects of ethanol. Neuroscience 71:417-427.

Givens BS, Olton DS (1990) Cholinergic and GABAergic modulation of medial septal area: effect on working memory. Behav Neurosci 104:849-855.

Green JD, Arduini AA (1954) Hippocampal electrical activity in arousal. J Neurophysiol 17:533-557.

Hagan JJ, Salamone JD, Simpson J, Iversen SD, Morris RGM (1988) Place navigation in rats is impaired by lesions of medial septum and diagonal band but not nucleus basalis magnocellularis. Behav Brain Res 27:9-20.

Hasselmo ME, Bower JM (1993) Acetylcholine and memory. Trends Neurosci 16:218-222.

Hays WL (1994) Statistics, Ed 5. Orlando, FL: Harcourt Brace.

Hepler DJ, Olton DS, Wenk GL, Coyle JT (1985) Lesions in nucleus basalis magnocellularis and medial septal area of rats produce qualitatively similar memory impairments. J Neurosci 5:866-873.

Ikonen S, Tanila H, Riekkinen Jr P, McMahan R, Gallagher M, Eichenbaum H (1998) Effect of selective immunotoxic lesion of the septal cholinergic cells on hippocampal place cells. Soc Neurosci Abstr 24:185.

Jakab RL, Leranth C (1995) Septum. In: The rat nervous system, Ed 2 (Paxinos G, ed), pp 405-442. New York: Academic.

Jung MW, Wiener SI, McNaughton BL (1994) Comparison of spatial firing characteristics of units in dorsal and ventral hippocampus of the rat. J Neurosci 14:7347-7356.

King C, Recce M, O'Keefe J (1998) The rhythmicity of cells of the medial septum/diagonal band of Broca in the awake freely moving rat: relationship with behaviour and hippocampal theta. Eur J Neurosci $10: 464-477$.

Krzywkowski P, de Bilbao F, Senut MC, Lamour Y (1995) Age-related changes in parvalbumin and GABA-immunoreactive cells in the rat septum. Neurobiol Aging 16:29-40.

Kubie JL, Ranck Jr JB (1983) Sensory-behavioral correlates in individual hippocampal neurons in three situations: space and context. In: Neurobiology of the hippocampus (Seifert W, ed), pp 433-447. New York: Academic.

Leung LS, Martin L, Steward DJ (1994) Hippocampal theta rhythm in behaving rats following ibotenic acid lesion of the septum. Hippocampus 4:136-147.

Markowska AL, Olton DS, Givens B (1995) Cholinergic manipulations in the medial septal area: age-related effects on working memory and hippocampal electrophysiology. J Neurosci 15:2063-2073.

Markus EJ, Barnes CA, McNaughton BL, Gladden VL, Skaggs WE (1994) Spatial information content and reliability of hippocampal CA1 neurons: effects of visual input. Hippocampus 4:410-421.

Markus EJ, Quin YL, Leonard B, Skaggs WE, McNaughton BL, Barnes CA (1995) Interactions between location and task affect the spatial and directional firing of hippocampal neurons. J Neurosci 15:7079-7094

M'Harzi M, Jarrard LE (1992) Effects of medial and lateral septal le- sions on acquisition of a place and cue radial maze task. Behav Brain Res 49:159-165.

McMahan RW, Sobel TJ, Baxter MG (1997) Selective immunolesions of hippocampal cholinergic input fail to impair spatial working memory. Hippocampus 7:130-136.

Miettinen R, Sirviö J, Riekkinen Sr P, Laakso MP, Riekkinen M, Riekkinen Jr P (1993) Neocortical, hippocampal and septal parvalbuminand somatostatin-containing neurons in young and old rats: correlation with passive avoidance and water maze performance. Neuroscience 53:367-378.

Miller VM, Best PJ (1980) Spatial correlates of hippocampal unit activity are altered by lesions of the fornix and entorhinal cortex. Brain Res 194:311-323.

Mizumori SJY, McNaughton BL, Barnes CA, Fox KB (1989) Preserved spatial coding in hippocampal CA1 pyramidal cells during reversible suppression of CA3c output: evidence for pattern completion in hippocampus. J Neurosci 9:3915-3928.

Mizumori SJY, Perez GM, Alvarado MC, Barnes CA, McNaughton BL (1990) Reversible inactivation of the medial septum differentially affects two forms of learning in rats. Brain Res 528:12-20.

Mizumori SJY, Barnes CA, McNaughton BL (1992a) Differential effects of age on subpopulations of hippocampal theta cells. Neurobiol Aging 13:673-679.

Mizumori SJY, Ward KE, Lavoie AM (1992b) Medial septal modulation of entorhinal single unit activity in anesthetized and freely moving rats. Brain Res 570:188-197.

Mizumori SJY, Lavoie AM, Kalyani A (1996) Redistribution of spatial representation in the hippocampus of aged rats performing a spatial memory task. Behav Neurosci 110:1006-1016.

Muller RU, Kubie JL (1987) The effects of changes in the environment on the spatial firing of hippocampal complex-spike cells. J Neurosci 7:1951-1968.

Muller RU, Kubie JL, Ranck JB (1987) Spatial firing patterns of hippocampal complex spike cells in a fixed environment. $\mathrm{J}$ Neurosci 7:1935-1950.

O'Keefe J (1976) Place units in the hippocampus of the freely moving rat. Exp Neurol 51:78-101.

O'Keefe J, Conway DH (1978) Hippocampal place units in the freely moving rat: why they fire where they fire. Exp Brain Res 31:573-579.

O'Keefe J, Dostrovsky J (1971) The hippocampus as a spatial map. Preliminary evidence from unit activity in the freely-moving rat. Brain Res 34:171-175.

Ono T, Tamura R, Takamura Y, Nishijo H (1997) Responses of lateral septal neurons during performance of spatial tasks in rats. Soc Neurosci Abstr 23:1617.

Ranck Jr JB (1973) Studies on single neurons in dorsal hippocampal formation and septum in unrestrained rats. Part I. Behavioral correlates and firing repertoires. Exp Neurol 41:462-531.

Rapp PR (1998) Representational organization in the aged hippocampus. Hippocampus 8:432-435.

Rapp PR, Gallagher M (1996) Preserved neuron number in the hippocampus of aged rats with spatial learning deficits. Proc Natl Acad Sci USA 93:9926-9930.

Risold PY, Swanson LW (1997) Connections of the rat lateral septal complex. Brain Res Rev 24:115-195.

Samsonovich A, McNaughton BL (1997) Path integration and cognitive mapping in a continuous attractor neural network model. J Neurosci 17:5900-5920.

Shapiro ML, Simon DK, Olton DS, Gage III FH, Nilsson O, Björklund A (1989) Intrahippocampal grafts of fetal basal forebrain tissue alter place fields in the hippocampus of rats with fimbria-fornix lesions. Neuroscience 32:1-18

Shen J, Barnes CA (1996) Age-related decrease in cholinergic synaptic transmission in three hippocampal subfields. Neurobiol Aging $17: 439-451$.

Shen J, Barnes CA, Wenk GL, McNaughton BL (1996) Differential effects of selective immunotoxic lesions of medial septal cholinergic cells on spatial working and reference memory. Behav Neurosci 110:1181-1186.

Shen J, Barnes CA, McNaughton BL, Skaggs WE, Weaver KL (1997) The effect of aging on experience-dependent plasticity of hippocampal place cells. J Neurosci 17:6769-6782.

Shetty AK, Turner DA (1998) Hippocampal interneurons expressing glutamic acid decarboxylase and calcium-binding proteins decrease with aging in Fischer 344 rats. J Comp Neurol 394:252-269. 
Skaggs WE, McNaughton BL, Gothard KM, Markus EJ (1993) An information theoretic approach to deciphering the hippocampal code. In: Advances in neural information processing systems, Vol 5 (Hanson SJ, Cowan JD, Giles CL, eds), pp 1030-1037. San Mateo, CA: Morgan Kaufmann.

Stewart DJ, Vanderwolf CH (1987) Hippocampal rhythmical slow activity following ibotenic acid lesions of the septal region. I. Relations to behavior and effects of atropine and urethane. Brain Res 423:88-108.

Sutherland RJ, Rodriguez AJ (1989) The role of the fornix/fimbria and some related subcortical structures in place learning and memory. Behav Brain Res 32:265-277.

Tanila H, Shapiro M, Gallagher M, Eichenbaum H (1997a) Brain aging: changes in the nature of information coding by the hippocampus. J Neurosci 17:5155-5166.

Tanila H, Sipilä P, Shapiro M, Eichenbaum H (1997b) Brain aging: impaired coding of novel environmental cues. J Neurosci 17:5167-5174.

Thompson LT, Best PJ (1989) Place cells and silent cells in the hippocampus of freely-behaving rats. J Neurosci 9:2382-2390.

Thompson LT, Best PJ (1990) Long-term stability of the place-field activity of single units recorded from the dorsal hippocampus of freely behaving rats. Brain Res 509:209-308.
Torres EM, Perry TA, Blokland A, Wilkinson LS, Wiley RG, Lappi DA, Dunnet SB (1994) Behavioral, histochemical and biochemical consequences of selective immunolesions in discrete regions of the basal forebrain cholinergic system. Neuroscience 63:95-122.

Vertes RP, Kocsis B (1997) Brainstem-diencephalo-septohippocampal systems controlling the theta rhythm of the hippocampus. Neuroscience 81:893-926.

Wallenstein GV, Eichenbaum H, Hasselmo ME (1998) The hippocampus as an associator of discontiguous events. Trends Neurosci 21:317-323.

Walsh TJ, Herzog CD, Gandhi C, Stackman RW, Wiley RG (1996) Injection of IgG 192-saporin into the medial septum produces cholinergic hypofunction and dose-dependent working memory deficits. Brain Res 716:69-79.

Whishaw IQ, Jarrard LE (1995) Similarities vs difference in place learning and circadian activity in rats after fimbria-fornix section or ibotenate removal of hippocampal cells. Hippocampus 5:594-604.

Wilson MA, McNaughton BL (1993) Dynamics of the hippocampal ensemble code for space. Science 261:1055-1058.

Winson J (1978) Loss of hippocampal theta rhythm results in spatial memory deficit in the rat. Science 201:160-163. 